\title{
STUDY OF THE CLINICAL PROFILES OF NECROTISING FASCIITIS
}

\author{
Sanjeev Malhotra1, Abhishek Kansal2, Sanjay Datey3, Harshvardhan Rao ${ }^{4}$ \\ ${ }^{1}$ Resident, Department of General Surgery, Shri Aurobindo Medical College and Postgraduate Institute, Indore. \\ ${ }^{2}$ Assistant Professor, Department of General Surgery, Shri Aurobindo Medical College and Postgraduate Institute, Indore. \\ ${ }^{3}$ Professor, Department of General Surgery, Shri Aurobindo Medical College and Postgraduate Institute, Indore. \\ ${ }^{4}$ Resident, Department of General Surgery, Shri Aurobindo Medical College and Postgraduate Institute, Indore.
}

\section{ABSTRACT}

\section{BACKGROUND}

Necrotising fasciitis is a rapidly progressive and soft tissue destructive inflammation and infection involving the superficial fascia and muscle. Necrotising soft tissue inflammation and infection occurs predominantly in patients predisposed by compromised immunological status, diabetes mellitus or vascular insufficiency, HIV, neutropenia, hypoproteinaemia, COPD, etc. Clinical profile of necrotising fasciitis is variable and the clinical course can be fatal.

\section{MATERIALS AND METHODS}

This descriptive observational study of the clinical profile of necrotising fasciitis was undertaken in a tertiary care centre of central India. Study was conducted for a period of four years i.e. from July 2011 to September 2015 on retrospective and prospective basis. The collected data was analysed by descriptive statistical methods and presented in a tabular form.

\section{RESULTS}

Fifty-two patients of necrotising fasciitis were included in the study and the demographic profile, clinical presentations, morbidity and mortality were studied. Necrotising fasciitis patients present with systemic manifestations and develop the complications leading to death. Four patients (7.69\%) of 52 expired in spite of all efforts. Males were the common sufferers as we had 36 males of out the 52 patients. Diabetes mellitus was the commonest comorbid condition. In our study, most common organism was mixed flora in the pus culture and sensitivity followed by group A Streptococcus. Lower extremities were the commonest body parts to get necrotising fasciitis. Debridement was the most common surgical procedure performed in our study. Mean duration of hospital stay was 35.44 days.

\section{CONCLUSION}

Necrotising fasciitis leads to prolonged morbidity and significant mortality. Most of the patients had prolonged hospital stay and required multiple surgical procedures mainly debridement during the course of their treatment. Patients with provisional diagnosis of necrotising fasciitis should be treated aggressively with wound debridement as early as possible, if necessary, with grafting and broad-spectrum antibiotics. A high level of clinical alertness is needed in a patient with comorbid conditions presenting with the features that mimic necrotising fasciitis so that early diagnosis and early treatment can start and prevent the life of patients.

\section{KEYWORDS}

Necrotising Fasciitis, Diabetes Mellitus, Soft Tissue Infection, Polymicrobial.

HOW TO CITE THIS ARTICLE: Malhotra S, Kansal A, Datey S, et al. Study of the clinical profiles of necrotising fasciitis. J. Evolution Med. Dent. Sci. 2017;6(60):4388-4391, DOI: 10.14260/Jemds/2017/949

\section{BACKGROUND}

Necrotising fasciitis is a rapidly progressive and soft tissue destructive inflammation and infection involving the superficial fascia and muscle. Necrotising soft tissue inflammation and infection occurs predominantly in patients predisposed by compromised immunological status, diabetes mellitus or vascular insufficiency, HIV, neutropenia, hypoproteinaemia, COPD, etc. The most common cause of necrotising fasciitis is the entry of bacteria through the

Financial or Other, Competing Interest: None.

Submission 20-06-2017, Peer Review 14-07-2017,

Acceptance 20-07-2017, Published 27-07-2017.

Corresponding Author:

Dr. Abhishek Kansal,

\#103 Kunwar Princess Crown,

95 - 96, Shri Nagar Main,

Near Anand Bazaar Square,

Indore-452010.

E-mail:dr_kansal@yahoo.com

DOI: $10.14260 /$ jemds $/ 2017 / 949$ breach in the continuity of skin such as cut, scrap, burn or even a small puncture wound. Early suspicion of necrotising fasciitis is crucial as the patient survival is inversely related to the time interval between onset of inflammation and initiation of appropriate therapy. Several other factors also affect the morbidity and mortality in addition to early diagnosis and treatment.

Historically the group A beta-haemolytic Streptococcus was considered as a major culprit but now it has lost its position. Now many other bacteria such as Group A Streptococcus, Klebsiella, Clostridium, E. coli, Staphylococcus Aureus, Aeromonas hydrophila equally shares the credit. Polymicrobial infection tend to be more common finding in necrotising fasciitis than isolated organism and this combination or synergy is responsible for the rapid and aggressive destruction of soft tissue. Majority of cases of minor or trivial injury that were neglected are sometimes the precipitating event. It may be result of large infected wound or sometime may be due to some unsterile surgical procedures or can occur even after intravenous cannulation. 
It can be the result of scrotal or penile cellulitis or infection. Symptoms are confusing to the medical fraternity and can lead to delay in diagnosis and treatment.

Clinical profile of Necrotising Fasciitis is variable and the clinical course can be erratic. It needs urgent intervention on the part of surgeon to control the spread and eradicate the infection. Comorbid conditions play an important role in the overall outcome of the patient. We have conducted this study to find the pattern of necrotising fasciitis and its outcome in our region.

\section{MATERIALS AND METHODS}

This descriptive observational study was carried in the tertiary care hospital in central India for the time period of about four years. The data obtained retrospectively and prospectively from the patients of necrotising fasciitis admitted in the hospital during the specified time period was recorded. The diagnosis was made on the basis of clinical presentation and was supported with the investigation and intraoperative findings. Also, the comorbid conditions associated with the condition were recorded. Total of 52 patients were included in the study after detailed examination. The part of body involved and the total duration of hospital stay was recorded. The fluid/discharge from the wound was sent for culture and sensitivity. Patients with bed sores, localised subcutaneous collection and local wound infection were excluded. Patients who were less than 18 years of age were excluded and were treated in the Paediatric Surgery Department. The collected data was entered in a master chart and analysed by descriptive statistical methods. At no stage identity of individual was disclosed.

\section{RESULTS}

In this descriptive observational study, a total of 52 patients were included. They were observed on the basis of age, sex, comorbid conditions, site involved, spectrum of pus from the wound, types of surgery performed, duration of hospital stay, and the cause of death. Following tables depict the analysed data of our study.

\begin{tabular}{|c|c|c|}
\hline Age Distribution & No. of Cases & Percentage \\
\hline$<20$ Years & 2 & $3.8 \%$ \\
\hline $21-40$ Years & 18 & $34.6 \%$ \\
\hline $41-60$ Years & 21 & $40.4 \%$ \\
\hline 60 - 80 Years & 10 & $19.2 \%$ \\
\hline$>80$ Years & 1 & $1.9 \%$ \\
\hline \multicolumn{2}{|c|}{ Table 1. Distribution According to Age } \\
\hline
\end{tabular}

The maximum incidence of necrotising fasciitis was seen in the age group of 41 years to 60 years. The youngest patient was a 19-year-old and the oldest patient was an 80-year-old.

\begin{tabular}{|c|c|c|}
\hline Gender & No. of cases & Percentage \\
\hline Male & 36 & $69.2 \%$ \\
\hline Female & 16 & $30.8 \%$ \\
\hline \multicolumn{2}{|c|}{ Table 2. Distribution According to Gender } \\
\hline
\end{tabular}

Males were more commonly affected with necrotising fasciitis in comparison to women as they are more involved in outdoor activities. They had more chance of trauma to the extremities which can lead to necrotising fasciitis.

\begin{tabular}{|c|c|c|}
\hline Comorbidities & No. of Cases & Percentage \\
\hline Diabetes Mellitus & 25 & $48.1 \%$ \\
\hline Hypertension & 3 & $5.8 \%$ \\
\hline $\begin{array}{c}\text { Ischaemic Heart } \\
\text { Disease }\end{array}$ & 1 & $1.9 \%$ \\
\hline \multicolumn{2}{|c|}{$\begin{array}{c}\text { Table 3. Comorbid Conditions Associated } \\
\text { with Necrotising Fasciitis }\end{array}$} \\
\hline
\end{tabular}

The most common comorbid condition associated is type 2 diabetes mellitus followed by hypertension.

\begin{tabular}{|c|c|c|}
\hline Site of Involvement & No. of Cases & Percentage \\
\hline Chest and Abdomen & 5 & $9.6 \%$ \\
\hline Upper Limb & 5 & $9.6 \%$ \\
\hline Lower Limb & 42 & $80.76 \%$ \\
\hline Total Cases & 52 & $100 \%$ \\
\hline \multicolumn{2}{|c|}{ Table 4. Site of Involvement } \\
\hline
\end{tabular}

Lower limb was the most common site of involvement. As the lower limb was more prone to trauma (major or minor) and also the Comorbid condition affect the lower limb in form of neuropathy in diabetic patient and peripheral vascular disease and atherosclerosis in smokers and old age.

\begin{tabular}{|c|c|c|}
\hline Pus C/S & No. of Cases & Percentage \\
\hline Mixed flora & 28 & $53.8 \%$ \\
\hline Group A Streptococcus & 18 & $34.6 \%$ \\
\hline Staph. Epidermis & 3 & $5.8 \%$ \\
\hline $\begin{array}{c}\text { Coagulase negative } \\
\text { Staphylococcus Aureus }\end{array}$ & 2 & $3.8 \%$ \\
\hline $\begin{array}{c}\text { P. Aeruginosa and } \\
\text { Enterobacteriaceae }\end{array}$ & 1 & $1.9 \%$ \\
\hline \multicolumn{2}{|c|}{$\begin{array}{c}\text { Table 5. Spectrum of Pus C/S in } \\
\text { Necrotising Fasciitis Patients }\end{array}$} \\
\hline
\end{tabular}

In our study, most common organism was mixed flora in the pus culture and sensitivity followed by group A Streptococcus. Total 28 cases were affected by bacteria of mixed flora.

\begin{tabular}{|c|c|}
\hline Types of surgery & No. of cases \\
\hline Debridement & 50 \\
\hline Release incision & 32 \\
\hline SSG & 17 \\
\hline Amputation & 1 \\
\hline Incision \& drainage & 1 \\
\hline \multicolumn{2}{|c|}{ Table 6. Types of surgery performed } \\
to treat Necrotising Fasciitis
\end{tabular}

Fifty cases underwent debridement as initial procedure. Some patients required multiple debridements. 32 patients undergone release incisions as initial procedure. Few cases healed by secondary intention and secondary suturing were done in some cases. Subsequent split skin grafting was done as final procedure in 17 cases. Amputation was done in 1 case as a last resort to control infection and to save life. 


\begin{tabular}{|c|c|c|}
\hline Duration of Hospital Stay & No. of Cases & Percentage \\
\hline$<7$ days & 2 & $3.8 \%$ \\
\hline $7-14$ days & 1 & $1.9 \%$ \\
\hline $14-21$ days & 5 & $9.6 \%$ \\
\hline $21-28$ days & 7 & $13.5 \%$ \\
\hline $29-35$ days & 13 & $25 \%$ \\
\hline $36-42$ days & 6 & $11.5 \%$ \\
\hline $43-49$ days & 8 & $15.4 \%$ \\
\hline$>50$ days & 10 & $19.2 \%$ \\
\hline \multicolumn{2}{|c|}{ Table 7. Duration of Hospital Stay } \\
\hline
\end{tabular}

Most patients stayed in the hospital for 29 - 35 days. Mean duration of hospital stay was 35.44 days.

\begin{tabular}{|c|c|}
\hline Cause of Death & No. of Cases \\
\hline Septicaemia with MODS & 3 \\
\hline ARF & 1 \\
\hline Table 8. Cause of Death in Necrotising Fasciitis \\
\hline
\end{tabular}

Necrotising fasciitis patients present with systemic manifestations and develop the complications leading to death. The most common cause of death in necrotising fasciitis was septicaemia with multiorgan failure.

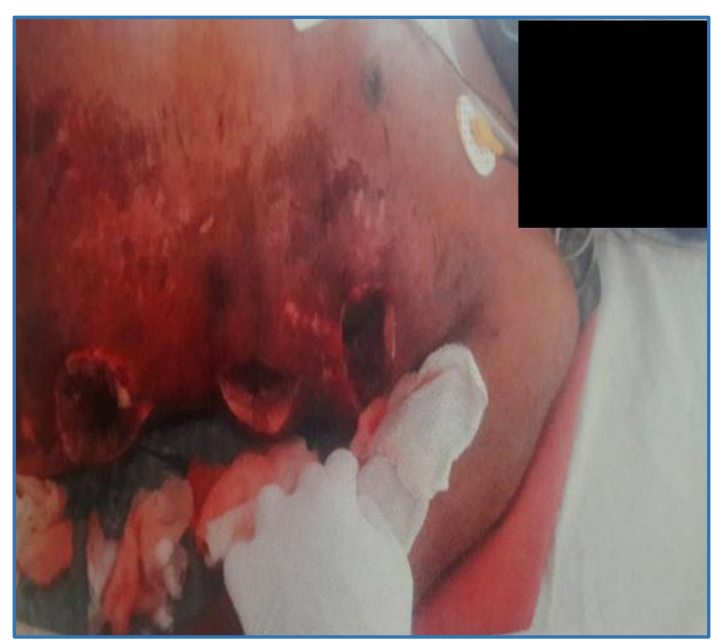

Figure 1. Necrotising Fasciitis of Chest Wall and Abdominal Wall

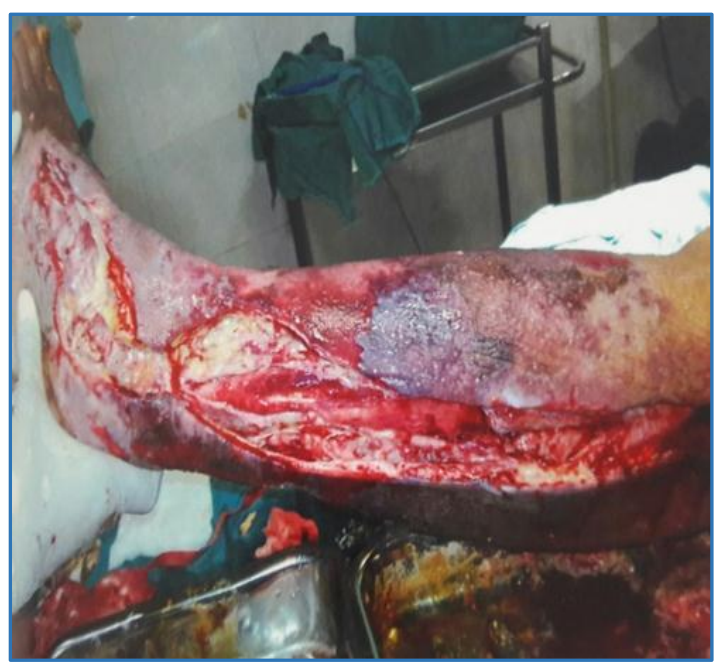

Figure 2. Necrotising Fasciitis of Lower Extremities with Initial Debridement

\section{DISCUSSION}

The term necrotising fasciitis was coined by Wilson in 1952.(1) Necrotising fasciitis is a rapidly progressive inflammatory infection of the fascia with secondary necrosis of subcutaneous tissue. Necrotising Fasciitis moves along the fascial plane.(2) Gangrene of scrotum and penis is a form of infection caused by haemolytic Streptococcus, is similar to necrotising fasciitis to the other part of the body.(3) Multiple risk factors for necrotising fasciitis are identified such as diabetes mellitus,(4) liver cirrhosis,(5) immune suppression, peripheral vascular disease, advanced age, etc. Necrotising fasciitis is classified into 2 types to reflect its bacterial aetiology. Type 1 infections are more prevalent and more dangerous and usually occur after trauma or surgery, and have a polymicrobial aetiology. Most commonly, this is nongroup A Streptococci in synergism with other aerobic and anaerobic organisms. Type 2 infections are of monomicrobial aetiology and often develop without an antecedent trauma. Group A, B-haemolytic Streptococcus and Staphylococcus aureus are the most common pathogens in this disease.(6) Monomicrobial necrotising fasciitis does not cause much mortality as compared to polymicrobial aetiology.

Early diagnosis and early treatment of the affected tissue was associated with reduction in morbidity and mortality.(7) Aeromonas hydrophila infection, Vibrio infection, cancer, hypotension, and band form white cell count greater than $10 \%$ are positive predictors of mortality while the presence of haemorrhagic bullae is a negative predictor of the mortality. Streptococcus and Staphylococcus infection are not predictors of mortality. ${ }^{(8)}$ The necrotising fasciitis involving the upper extremities has a higher mortality in comparison to other body parts as they are more prone to extend up to chest requiring more extensive debridement and long postoperative care for the complications. ${ }^{(9)}$

The classical presentation of necrotising fasciitis is intense pain and tenderness over the affected site. The pain may be out of proportion to the clinical findings in initial phase. The pain may proceed before the fever, malaise and myalgia. Sometimes pain may be present at a distant site other than the involved site.(10) Other variable clinical presentations are oedema of affected parts extending beyond the areas of erythema of affected part, skin eruptions and vesicles, and crepitus beneath the skin on palpation. Sometimes the affected tissue demonstrates a wooden, hardened feel in case of necrotising fasciitis.(7) The finger test is an established and easy test and can be performed in the ward or casualty under local anaesthesia or general anaesthesia. The absence of normal blood flow, dirty dishwater coloured fluid and discolouration of fat strongly supports the diagnosis.(11) There are various presentations of necrotising fasciitis ranging from stage I to stage III. The signs and symptoms range from warm, swollen and erythematous skin followed by blistering of skin, bullae to skin crepitus, necrosis and anaesthesia.(12)

The most common comorbid condition associated in our study was diabetes mellitus. The result obtained was compared with other studies done on necrotising fasciitis patients. Similar results were obtained in the other studies.(2),(13) The most common site of involvement was lower limb in our study. The most common gender affected in our study was male. Similar results were obtained in a study done by Vineed $S$ et al.(13) In our study, the predominant 
organism was mixed flora seen in 28 patients followed by group A Streptococcus resembling to other study.(13) Mean duration of hospital stay was 35.44 days which was less than other studies compared (40.6 days).(14) The mean age of presentation in our study was 47.21 years which was near similar to study done by Wong et al.(14)

Mortality rate in our study was $7.69 \%$ which is comparatively low when compared to Wong et al.(14) Early recovery depends upon how early patients present to the hospital with early recognition of the features of necrotising fasciitis. The antibiotic coverage plays an important role but it will not replace the role of early surgical intervention in the form of debridement/release incision and removal of the focus of infection from the wound. So, a surgeon should not hesitate in exploration of wound whenever in doubt rather than leaving the bacteria inside and allowing bacterial proliferation causing necrotising fasciitis.

\section{CONCLUSION}

Necrotising fasciitis is a relatively rare surgical emergency and can confuse the treating doctors. If not diagnosed in time then the morbidity and the mortality of the patient increases. Comorbid conditions also precipitate the disease. A high level of clinical alertness is needed in a patient with Comorbid conditions presenting with the features that mimic necrotising fasciitis so that early diagnosis and early treatment can start and prevent the life of patients. Despite of all measures there is a high rate of morbidity and mortality.

\section{REFERENCES}

[1] Wilson B. Necrotizing fasciitis. Am Surg 1952;18(4);416-31.

[2] Smith AJ, Daniels T, Bohnem JM. Soft tissue infections and the diabetic foot. Am J Surg 1996;172(Suppl 6A):7S-12S.

[3] Meleny FL. Hemolytic Streptococcus gangrene. Arch Surg 1924;(2):317-64.
[4] Bahebeck J, Sobgui E, Loic F, et al. Limb threatening and life threatening diabetic extremities: clinical patterns and outcomes in 56 patients. J Foot Ankle Surg 2010;49(1):43-6.

[5] Hung TH, Tsai CC, Tseng CW, et al. Liver cirrhosis as a real risk factor for Necrotizing fasciitis: a three year population based follow up study. Singapore Med J 2014;55(7):378-82.

[6] Andreasen TJ, Green SD, Childers BJ. Massive infectious soft tissue injury: diagnosis and management of Necrotizing Fasciitis and purpura fulminans. Plast Reconstr Surg 2001;107(4):1025-35.

[7] McHenry CR, Piotrowosky JJ, Petrinic D, et al. Determinants of mortality for necrotizing soft tissue infections. Ann Surg 1995;221(5):558-65.

[8] Hsiao CT, Weng HH, Yuan YD, et al. Predictors of mortality in patients with Necrotizing Fasciitis. Am J Emerg Med 2008;26(2):170-5.

[9] Cheng NC, Su YM, Kuo YS, et al. Factors affecting the mortality of Necrotizing Fasciitis involving the upper extremities. Surg Today 2008;38(12):1108-13.

[10] Olafsson EJ, Zeni T, Wilkes DS. A 46 year old man with excruciating shoulder pain. Chest 2005;127(3):103944.

[11] Childers BJ, Potyondy LD, Nachreiner R, et al. Necrotizing Fasciitis: a 14 year prospective study of 163 consecutive patients. American Surgeon 2002;68(2):109-16.

[12] Wang YS, Wong CH, Tay YK. Staging of Necrotizing Fasciitis based on the evolving cutaneous features. Int Dermatol 2007;46(10):1036-41.

[13] Vineed S, Santoshkumar. Predisposing conditions of Necrotizing Fasciitis: an observational study. IJSR 2017:6(2).

[14] Wong CH, Wang YS. The diagnosis of Necrotizing Fasciitis. Current Opinion in Infectious Diseases 2005;18(2)101-6. 